\title{
Pueblos indios y PROPIEDAD en la Alcaldía Mayor de La Barca durante el VirReinato
}

\author{
Ramón Goyas Mejía
}

Resumen: Este trabajo es un análisis sobre el proceso de apropiación de la tierra entre los pueblos indios de la Alcaldía Mayor de La Barca durante los siglos XVII y XVIII. En él se destacan las condicionantes económicas, demográficas y de control político que dieron como resultado una forma asimétrica del reparto del espacio, enfatizando también en las relaciones de complementariedad y de choque entre los pueblos y entre éstos y los dueños de ranchos y grandes propiedades, cuyo giro productivo principal fue la ganadería menor; estas relaciones tendieron a volverse cada vez más problemáticas, sobre todo durante el siglo XVIII con la recuperación demográfica indígena y la necesidad de más tierras para el sustento de las comunidades.

Palabras clave: Fundo legal, pueblos indios, propiedad comunal, tenencia de la tierra, virreinato.

Enviado a dictamen: 22 de agosto de 2011 Aprobación: 10 de noviembre de 2011 Revisiones: 1

Ramón Goyas Mejía, doctor en Ciencias Sociales por el Colegio de Jalisco, es investigador de tiempo completo de la Universidad de Guadalajara, temas de especialización: tenencia de la tierra, pueblos indígenas y conflictos agrarios durante la época colonial. Correo electrónico: ramongoyas@yahoo.com.mx,ramon.goyas@profesores.valles.udg.mx.
Abstract: This work is an analysis on the process of appropriation of the land among the Indian towns of the greater mayorship of $\mathrm{La}$ Barca during the XVII and XVIII centuries. In it, the following economic conditioners stand out: demographic and political control that gave as result an asymmetric form of the distribution of the space, also emphasizing in the relations of complementariness and shock among the towns and among these and the owners of the farms and great properties whose main productive turn was the smaller cattle ranch; relations that tended to mainly become more and more problematic during century XVIII with indigenous the demographic recovery and the necessity of more earth for the sustenance of the communities.

Keywords: Legal fund, indigenous peoples, communal ownership, land tenure, viceroyalty.

\section{Introducción}

E presente trabajo es parte de un proyecto más vasto sobre el comportamiento de la propiedad corporativa de los pueblos durante virreinato para el occidente de México. Por diversos autores sabemos que durante la época colonial los pueblos indígenas gozaron de tierras de fundo legal, de cofradías y de las llamadas tierras de comunidad. En la Nueva Galicia, y más concretamente en el caso 
de la alcaldía mayor de Poncitlán, la densidad de los pueblos indígenas - ubicados casi todos en una franja aledaña al río Grande o Santiago y en las orillas del lago de Chapala - originó conflictos por las tierras que por ley debían poseer. En contraparte, al norte de dicha franja se conformaron grandes latifundios que en conjunto abarcaron cientos de miles de hectáreas, es decir, acapararon la mayor parte de tierras de la jurisdicción ya mencionada. Este fenómeno fue el resultado de un complicado proceso que duró por lo menos dos centurias, culminando con enfrentamientos cada vez más recurrentes entre los diversos dueños de la tierra en la jurisdicción.

Los estudios regionales expresados en análisis acotados en tiempo y espacio, han abierto brecha en las últimas décadas, bajo la premisa de que ningún hecho social puede ser comprendido fuera del contexto en que se origina, y de que puede manifestar en sus múltiples relaciones la totalidad social (Viqueira, 1992). Una de las principales contribuciones de los análisis regionales de conflicto por la tierra, es que permite revelar detalles que los estudios generales no aportan en torno a las complejas relaciones entre campesinos, indígenas y el resto de la estructura social en un contexto de tiempo y lugar específico. El otro aporte es sin duda el comparativo, es decir, ayuda a encontrar las similitudes y diferencias con los procesos históricos de otras regiones y, con ello, establecer regularidades, es decir, fortalecer explicaciones ya planteadas de acción social para otros casos estudiados; o bien, por el contrario, cuestionar las ideas y tendencias generales aceptadas por investigadores de los fenómenos históricos generando nuevas interrogantes y posibles respuestas.

La relación entre población y el aprovechamiento del medio nos remite necesariamente al aspecto espacial o geográfico que actúa como receptáculo de las actividades del ser humano; sin embargo, contra una visión estática y neutral del espacio que inhibe un panorama analítico del mismo, en cuanto no considera que en él se inscriben o superponen diferencias culturales, memoria histórica y organizaciones sociales en disputa (Gupta y Ferguson, 1997), dicho espacio es moldeado y trasformado tendiendo a convertirse en un ente dinámico (Lameiras, 1993); en términos de Lefebvre (1991), se pasa así de la producción en el espacio a la producción del espacio. Para el caso de los pueblos indios, entendidos no sólo como conglomerados de población nativa, sino como instituciones con antecedentes prehispánicos pero insertos en un modelo de organización hispano en constante cambio, se pueden plantear de entrada serias interrogantes: ¿Por qué los pueblos se ubicaron en ciertos lugares y no en otros? ¿Cuál es la relación entre su ubicación virreinal y su pasado prehispánico? Transversalmente, ies acertado relacionar la ausencia o presencia de conflictos por la tierra con la densidad de asentamientos indígenas y el paulatino aumento de población de todas las etnias, visible sobre todo durante el siglo XVIII?, ¿Cuál fue la relación no sólo económica, sino de mestizaje cultural entre haciendas, pueblos y ranchos?

Sabemos que, para el caso de las haciendas del occidente de México, una condición indispensable para su éxito económico era su ubicación cercana a los pueblos indios, quienes fungieron así como fuente segura de mano de obra. La existencia de pueblos y el respeto que los hacendados debían guardar en torno a las tierras indígenas como espacios vitales necesarios para su reproducción, es uno de los aspectos más contradictorios y problemáticos de la historia agraria; sabemos menos aún de la relación entre pueblos indios y ranchos, a pesar de ser éstos últimos ya desde el siglo XVIII las unidades rurales mayoritarias en el occidente de México (ver figura 1).

Una forma promisoria de hacer historia regional es la que plantea acercarse a lo general a través de lo particular, o, en términos de Viqueira, la historia regional "como laboratorio" (1992), la cual busca arrojar nueva luz de lo nacional a partir de lo local. Así, a problemas históricos cuya resolución a nivel general ha resultado poco satisfactoria, se propone replantearlos 
a nivel regional, esperando que las relaciones entre los actores aparezcan con mayor nitidez. Siguiendo este planteamiento, se tomó como unidad de análisis a la alcaldía mayor de Poncitlán y La Barca durante el periodo colonial, en cuanto, analizando la propiedad de la tierra en la antigua Nueva Galicia, se observó que, de sur a norte, esta jurisdicción política contenía una franja con 23 pueblos de origen indígena, algunos a menos de una legua de distancia, seguida de un cinturón de grandes haciendas ganaderas y, ya desde principios del siglo XVII, entreverados entre los fundos legales de los pueblos, una serie de predios familiares llamados "ranchos". Metodológicamente, más que ser representativa de la realidad de la época, la alcaldía mayor de La Barca poseía rasgos fuertemente acentuados para el fenómeno que aquí interesa, y más que bloques separados con formas de organización económica y rasgos culturales propios, se trataba de espacios jerárquicamente interconectados, de ahí el reto de pensar dicha diferencia a través de la interconexión (Gupta y Ferguson, 1997).

Se partió de la premisa de generar nuevo conocimiento mediante un estudio de larga duración, comparando distintos momentos históricos para comprender las profundas trasformaciones que en torno a la tenencia de la tierra se fueron generando en un mismo espacio jurisdiccional. A nivel local, el trabajo analizó población y territorio como dos factores cruciales en la trasformación de la propiedad durante los tres siglos de dominación hispana, más no como un proceso estable sino contradictorio, en cuanto contempló la fragmentación del espacio mediante la complementariedad y el choque constante de la propiedad de los pueblos como forma colectiva de apropiación, y la propiedad de las haciendas y ranchos como propiedad privada.

A nivel externo, se tomaron en cuenta los condicionamientos macrosociales que impusieron distintas normatividades y comportamientos debido a decisiones políticas que repercutieron profundamente en la tenencia de la tierra. En ese tenor, tal vez las medidas más importantes fueron las sucesivas "composiciones" de las propiedades en la Nueva España y la Nueva Galicia implementadas por las autoridades españolas en lapsos aproximados de cincuenta años: 1591, 1640, 1692 y 1754, con el fin de regular la propiedad de los recursos naturales en sus dominios.

Si bien, durante el periodo colonial las prerrogativas de los pueblos quedaron claramente establecidas en la Recopilación de Leyes de Indias, el ejercicio de éstas fue fruto de una serie de condicionamientos, tanto políticos como de correlación de fuerzas y presión local sobre los recursos, situación que a fines del siglo XVIII se volvió más complicada, al punto de culminar en enfrentamientos contra el poder hispano. Retomando a Lefebvre (1991), podemos decir que, la delimitación aquí retomada, en cuanto atiende a criterios administrativos, está indisolublemente asociada por su dimensión política, dimensión más clara y determinante a medida que el virreinato se fue consolidando y las contradicciones internas se hicieron más evidentes demandando el ejercicio efectivo de la violencia.

El análisis se centra en un desglose del reparto del espacio como fenómeno regional en tres momentos: por un lado, a partir de la llegada de los españoles al occidente de México y el cambio de la organización social hasta entonces imperante, lo cual trajo consigo una trasformación profunda de las formas de apropiación de la tierra (Carbó, 1996: 23); por el otro, la consolidación de la propiedad agraria durante el siglo XVII, particularmente durante el elusivo lapso que va de 1630 a 1750, periodo que se destaca entre otras causas por ser una de las épocas menos sometidas al escrutinio de los historiadores; por último, se hizo un análisis de la situación de la propiedad rural de la región elegida en las últimas décadas del siglo XVIII, etapa relevante no sólo por ubicarse en el preludio de la gesta de Independencia de México, sino porque, en sí misma, representa una especie de síntesis de fenómenos que durante dos siglos y medio se fueron generando, al punto 
que más que periodo de ruptura, creemos, representa una continuidad con el pasado.

\section{Pueblos y propiedad de la tierra durante el siglo XVI y XVII}

En 1529, a su llegada al territorio que luego se llamaría alcaldía mayor de Poncitlán y La Barca, los conquistadores españoles, más veinte mil guerreros tarascos, tlaxcaltecas y mexicanos capitaneados por Nuño Beltrán de Guzmán, se encontraron con una gran cantidad de aldeas y comunidades indígenas de importancia agrupados en los cacicazgos de Coina (o Coynan), Zula y Cuitzeo. Si bien Coina se entregó sin luchar, no pasó lo mismo con Cuitzeo, cuyo cacique y su gente opusieron resistencia a las huestes castellanas al intentar éstos cruzar el río Santiago y tomar por la fuerza las poblaciones inmediatas. El cronista Mota Padilla narra cómo los españoles, desde un cerro cercano al pueblo de Zula, se quedaron admirados de la gran cantidad de poblaciones establecidas alrededor del Lago de Chapala, algunas de las cuales contaban con templos o "cues" y construcciones bien remozadas (De la Mota, 1856: 71-79). Se calcula que en 1530 había establecidos en esta área unos 32 mil habitantes indígenas (Gerhard, 1996: 92). Estos pueblos, desde mucho tiempo atrás, marcaban el límite del área más poblada y sedentaria conocida como Mesoamérica, en contraste con el norte del río Santiago, cuya área de transición era recorrida por grupos nómadas tecuexes y guamares dedicados usualmente a la recolección y al pillaje (Powell, 1977).

Una década después, con el levantamiento indígena de la Guerra del Mixtón, se trastocó seriamente la trayectoria demográfica local. Según el padre Frejes (1833: 128-129), la batalla decisiva en el área se dio en un cerro cercano a Coina, donde más de 30 mil indígenas trataron de contener al ejército del virrey Antonio de Mendoza, compuesto de unos 60 mil hombres. La situación se dio en 1541, cuando las fuerzas virreinales avanzaron hacia el occidente de México para lograr el control de dicha rebelión, que amenazaba con arrasar las conquistas conseguidas durante la travesía de Nuño de Guzmán. A diferencia de otras batallas de la Guerra del Mixtón, los cronistas nos han legado poca información del enfrentamiento en Coina; se sabe sin embargo que, luego de diez días de asedio en que los españoles y sus aliados por fin tomaron el peñol de Coina, los indígenas insurrectos trataron de quitarse la vida por todos los medios, “...ya que estos bárbaros no trataban de ofender a sus enemigos, sino de quitarse la vida y quitarla a los suyos, y como perros rabiosos se embebecían en consumar la depravada resolución de ser primero muertos a darse a partido" (Mota-Padilla, 1856 305-306). Con todo, el virrey Antonio de Mendoza aún pudo hacer más de dos mil esclavos de los sobrevivientes de esta carnicería. De manera lapidaria, al rememorar esta batalla, fray Antonio Tello dejó registrado que, para 1652, año en que escribió su crónica, quedaban en Coina menos de ocho indios sobrevivientes (Tello, 1973: 295).

Uno de los efectos más visibles luego de la gran rebelión de 1540-1541, fue el despoblamiento de vastas llanuras en los alrededores de Zapotlán del Rey, Tototlán y Atotonilco. En esa dinámica desaparecieron pueblos como San Miguel de Acámbaro, en donde luego se extendió el latifundio de Jalpa de Cánovas (Brading, 1988: 72); ${ }^{1}$ Huáscato, pueblo tributario de la Corona Española desaparecido en $1560,{ }^{2}$ cuyas tierras luego conformarían una hacienda del mismo nombre, o Coina, cuyas tierras pasaron a las haciendas de Ciénega y Santa Ana Pacueco (Gutiérrez, 1955:254). Con la decadencia de algunos de estos pueblos, y para consolidar la ocupación definitiva del área amenazada de continuo por ataques chichimecas, se promovió también la entrega de enormes espacios a soldados españoles y funcionarios de la Nueva Galicia, casi siempre mediante mercedes de sitios de tierra de ganado mayor y menor.

James Lockhart (1997) critica la relación entre la despoblación indígena y la ocupación española de tierras, señalando que generalmente dicha ocupación se dio más bien cuando su explotación directa resultó 
lucrativa. Las evidencias disponibles en el caso aquí tratado, apuntan efectivamente a que la ocupación de la tierra, o más concretamente su explotación, no fue inmediata a la despoblación indígena, más no así la concesión legal de mercedes de sitios de ganado mayor y menor, contraviniendo incluso los ordenamientos reales que señalaban que las tierras desocupadas por pueblos indios desaparecidos o congregados en otros lugares no debían pasar a manos de conquistadores o colonos hispanos. Algunos virreyes fueron enfáticos en ello, como lo demuestran los ordenamientos del 17 de noviembre de 1599 y del 28 de febrero de 1603 , promovidos por don Gaspar de Zúñiga y Acevedo, conde de Monterrey, y el del 6 de mayo de 1606, por el virrey Conde de Montesclaros. ${ }^{3}$

Sin contar las tierras concedidas a los pueblos de indios, de 1539 a 1619, en la jurisdicción de la alcaldía mayor de Poncitlán se entregaron al menos 66 sitios de ganado mayor, 32 sitios de ganado menor y unas 98 caballerías de tierra; es decir, en equivalencias modernas, alrededor de 145 mil hectáreas (considerando 1,755 hectáreas aproximadas por sitio de ganado mayor, 780 hectáreas para los sitios de ganado menor y 42.7 hectáreas por cada caballería). Para hacer el conteo de estas cifras, se analizaron por casi dos años los títulos primordiales de las haciendas y estancias locales, información existente en el Archivo de Instrumentos Públicos de Jalisco, tratando de no dejar ninguna propiedad privada sin contabilizar. Obviamente, la cifra pudo ser mayor en función de que es probable que muchos documentos se hayan perdido o que simplemente no hayan sido considerados en este conteo. Una de las mercedes más notables por su extensión, fue la que el conquistador Juan de Villaseñor y Orozco, encomendero de Pénjamo, Huango y Atotonilco, consiguió del gobernador Francisco Vázquez de Coronado, el 2 de julio de 1544, consistente en 14 sitios de ganado mayor, cada uno con una caballería de tierra; ${ }^{4}$ como si no fuera suficiente esta enorme extensión, el 14 de julio de ese mismo año, el mismo personaje logró otra concesión por cuatro sitios de ganado mayor más cuatro caballerías; ${ }^{5}$ es decir, sólo en estas dos entregas reunió más de 30 mil hectáreas en la jurisdicción. ${ }^{6}$ En sus adquisiciones quedaron las tierras del pueblo desaparecido de Acapo, también llamado Valle Florido, ubicado en las cercanías de la actual ciudad de Arandas.

Si bien la desaparición de las antiguas poblaciones permitió tanto la creación de la hacienda como la proliferación del ganado, los indígenas eran necesarios para el cultivo de la tierra y el sostenimiento de tributos por lo que la Corona Española se preocupó por garantizar su preservación. Como lo señala Friedrich Katz (2004: 79), la época colonial pudo ser la única época en la historia de México, antes de la revolución de 1910, en la que el Estado llevó a cabo un esfuerzo consciente para proteger a los derechos corporativos de los pueblos (ver figura 1).

Para pacificar definitivamente el área se llevaron a cabo importantes movimientos demográficos, lo que implicó una redistribución del espacio. Dicho fenómeno, promovido en la segunda mitad del siglo XVI, tanto por la Real Audiencia de Guadalajara como por los sucesivos virreyes de la Nueva España, tuvo serias repercusiones. De este modo, se fortaleció la tendencia prehispánica a la concentración de pueblos en los alrededores del lago de Chapala y en las orillas del río Santiago (llamado entonces Río Grande), donde quedaron ubicadas también las sedes de los poderes civil y religioso. No es fortuito que los frailes franciscanos hayan construido convento en Poncitlán desde 1533, dos años después de levantar su primer claustro en Tetlán, para atender las necesidades espirituales de los pueblos indígenas inmediatos (Tello, 1945: 116).

En síntesis, y como se puede observar en el siguiente mapa, ya para principios del siglo XVII se había generado una especie de separación de dos áreas distintas aunque profundamente interrelacionadas en lo económico: hacia el Sur, un cinturón de pueblos indios a ambos lados del Río Grande, a veces con una gran cercanía, lo cual con el tiempo ocasionaría conflictos por límites; 
estas congregaciones, como todas las de su clase, gozaban de una relativa autonomía y poco participaban en el mercado colonial; sin embargo, jurídicamente fueron un rival formidable contra las pretensiones expansionistas de los futuros latifundios coloniales (ver figura 2).

Hacia el norte del Río Grande, en cambio, se conformó un área controlada por grandes haciendas de ganadería menor que en conjunto acapararon más de medio millón de hectáreas y que, desde Pénjamo, en la Nueva España, se extendieron por las jurisdicciones de La Barca, Lagos y el corregimiento de Colimilla y Matatlán, entre las que destacan las haciendas de Santa Ana Pacueco, Ciénega, Milpillas, Cerro Gordo, Jalpa de Cánovas, a más de unas 35 mil hectáreas que para fines del siglo XVII pertenecían al marquesado del Villar y Águila, en las cercanías de Zapotlán del Rey y Poncitlán. Esta segunda zona fue crucial no sólo a nivel regional, sino para las redes de mercado de la Nueva España, ya que periódicamente se agostaban en ella miles de reses, pero sobre todo cientos de miles de ovejas provenientes de Querétaro, Toluca y Valladolid, hatos que a fines de cada año llegaban a invernar en el área. En efecto, diversos cronistas del siglo XVII mencionan los grandes rebaños que periódicamente venían a agostar a los llanos de Poncitlán. Algunos, como Fray Antonio Vázquez de Espinoza, calculan que anualmente llegaban en el invierno a esta zona hasta dos millones de ovejas, por ser región más templada y húmeda que el Altiplano (De Arregui, 1980: 62). Todas estas grandes propiedades tuvieron en común el pertenecer en distintos momentos históricos a ganaderos o a prósperos comerciantes avecindados en Querétaro o en la Ciudad de México; su actividad económica, por tanto, estaba poco vinculada a Guadalajara, y sus envíos, tanto de borregos como de remesas económicas, se destinaban hacia Querétaro, Valladolid o la capital del virreinato. De hecho, muchas de estas grandes propiedades no pagaban diezmo en Guadalajara, sino en Valladolid, donde se encontraba la sede del obispado al que pertenecían.
Un tercer factor que complicó la tenencia de la tierra de los pueblos fue la presencia temprana de dispersos asentamientos de criollos y mestizos, que, de modo familiar, comenzaron a adueñarse de pequeñas porciones de tierra entrando en competencia con haciendas y pueblos. Este tercer elemento es poco evidente a principios de la época colonial; sin embargo, gradualmente iría cobrando fuerza hasta convertirse en un serio competidor en la última centuria del Virreinato.

Si la propiedad familiar de índole ranchera se desarrolló tempranamente en los alrededores de Poncitlán y La Barca fue porque encontró las condiciones propicias para hacerlo. Este proceso se dio en detrimento de las tierras de los pueblos indígenas asentados, como ya se dijo, de modo denso en el área. Por ejemplo, el 4 de septiembre de 1570, el conquistador Diego Vázquez consiguió una merced consistente en una caballería de tierra por parte de don Juan Bautista de Orozco, oidor y visitador de la Nueva Galicia a orillas del pueblo de Ocotlán. ${ }^{8}$ A fines del siglo XVI dicha caballería había pasado a Domingo de Chávez y éste la cedió el 8 de abril de 1620 a María de Estrada. Ya en 1687, dicha caballería le pertenecía a Marcos Flores. En 1698, en el marco de la revisión de títulos de tierras de todas las provincias del Imperio español, el oidor Francisco Feixoo Centellas despachó título de composición de esta misma caballería a varios dueños o parcioneros que, para entonces, la estaban detentando. El 4 de agosto de 1755, Antonio Flores y otros dueños lograron nuevamente componerla ante Martín Blancas, juez supernumerario de tierras de la Audiencia de Guadalajara. ${ }^{9}$ Las evidencias disponibles en los archivos de tierras demuestran quela disminución de la población indígena durante el siglo XVI y XVII ocasionó que se entregaran mercedes de tierras casi en las goteras de las poblaciones sin mucha resistencia de éstas, a tal punto que durante el siglo XVIII, muchas haciendas y ranchos efectivamente contaban con títulos primordiales que a todas luces violaban los ordenamientos de las Leyes de 
Indias por estar ocupando parte de los fundos legales de los pueblos.

A diferencia del fundo legal de los pueblos comprendidos en la Audiencia de México, cuya extensión era de 1,200 varas en cuadro, es decir, alrededor de 101 hectáreas, en el caso de la Nueva Galicia, los fundos legales de las repúblicas indígenas medían casi 18 veces más, es decir, una legua cuadrada, lo que en términos actuales equivaldría a unas 1,755 hectáreas. Este contraste ya había sido destacado a principios del siglo XX por Lucio Mendieta y Núñez (1937: 64-69) y recientemente por Dorothy Tanck de Estrada (2010: 33-36). La implicación que estas formas de dotación tuvieron en ambas jurisdicciones aún espera un análisis detallado, aunque, para el caso de los pueblos comprendidos bajo la jurisdicción de Guadalajara, puede plantearse que un fenómeno derivado de este tipo de concesión fue la masificación de la ganadería mayor entre las repúblicas indígenas gracias a que podían contar con agostaderos para ello.

En el área de Ocotlán y La Barca, algunas medianas propiedades nombradas en la colonia indistintamente como ranchos y haciendas, nacieron también por compra de algunos girones de tierras a latifundios locales. Así por ejemplo, el puesto de Los Gachos (que en el siglo XVIII ya se le llamaba "hacienda") se conformó por compra de 3 caballerías que Marcos Núñez Lambaren hizo a doña Francisca Morelos, vecina de Guadalajara y heredera de la hacienda de Atequiza; eran tierras que se internaban a modo de cuña ente los pueblos de Santa María y Santa Cruz, y habían sido mercedadas originalmente el 15 de septiembre de 1570 a Pedro Flores de Arellano por el oidor Juan Bautista de Orozco. El 27 de mayo de 1579, Gerónimo de Orozco, presidente de la Real Audiencia de la Nueva Galicia, concedió a un licenciado Sánchez, abogado de la misma Real Audiencia otras 2 caballerías de tierra ubicadas entre los pueblos de Poncitlán y Santa Cruz. En el siglo XVIII dicha propiedad, consistente en 5 caballerías, fue compuesta por Marcos Núñez de Lambaren, quien logró agregar poco más de otra caballería de tierra realenga por la que pagó 50 pesos, incluida la media anata. ${ }^{10}$ En 1765 todas estas caballerías habían pasado a manos de Diego Pérez de Vargas, un ambicioso y audaz propietario que en aras de expandirse entró en conflicto constante con los pueblos aledaños.

En las cercanías de Atotonilco el Alto y de la actual ciudad de Arandas, encontramos también casos de entregas de sitios de tierra como El Nopal, Manantiales, El Ocote, El Carrizal y otros, que, por herencias sucesivas, conformaron ranchos desde mediados de la época colonial, es decir, que surgieron como propiedades familiares que con el tiempo tendían a fragmentarse casi siempre por sucesivas herencias. Es significativa también la acentuada consanguinidad de los oriundos de este tipo de asentamientos. ${ }^{11}$ Como estos casos, se podrían seguir citando muchos más para sustentar que, en general, la propiedad ranchera no fue un fenómeno del siglo XIX como algunos historiadores han propuesto para el área de estudio, sino que sus raíces arrancan prácticamente desde el siglo XVI, y estuvo interrelacionada casi siempre con la existencia de pueblos indígenas cercanos.

La tenencia de la tierra como bien limitado no se puede pensar por sí misma; para entender su funcionamiento es necesario partir del papel que juega como mercancía, es decir, sujeta a las leyes de la oferta y la demanda. Si tomamos en cuenta que las relaciones económicas durante el Virreinato fueron transformándose a medida que pasó el tiempo, debemos señalar que, en términos generales, durante la segunda mitad del siglo XVI la tierra se repartió en grandes bloques y que fueron precisamente estas entregas el origen de los grandes latifundios que se extendieron al norte del río Santiago.

Durante el siglo XVII continuó esta tendencia, pero más que entregas de mercedes de tierras baldías, lo que caracteriza a dicha centuria es la búsqueda de una delimitación clara en torno a la posesión de las grandes propiedades ya constituidas. No se han encontrado 
evidencias que demuestren que las composiciones de tierras promovidas por el rey Felipe II en su cédula del 1 de noviembre de 1591, hayan tenido algún impacto importante en torno a la conformación de la propiedad en el occidente de México. No pasa lo mismo, sin embargo, con las composiciones de mediados y fines del siglo XVII. A fines del siglo XVI apenas se comenzaba a dar la compactación de grandes unidades territoriales. Bajo esta premisa, tenemos aquí la génesis de los latifundios del occidente de México en manos de una sola familia; propiedades que, con las composiciones de 1640-1645, y luego con las de 1692, adquirieron un carácter legal, casi siempre mediante el pago de módicas cantidades. Las composiciones de tierras de 1640-1645 y de 1692-1696 que, en general no han sido tomadas en cuenta por los historiadores, fueron cruciales, ya que le otorgaron carácter legal a la mayoría de la tierra comunal y privada de la Nueva Galicia. En ese sentido, no sólo los pueblos se vieron beneficiados, sino que las grandes haciendas tuvieron la oportunidad de mostrar sus gruesos volúmenes de títulos primordiales acumulados para que fuesen reconocidos por las autoridades de la época y, mediante módicas cantidades, lograr "componer" la tierra de la cual se habían adueñado de modo consuetudinario. En cambio, las composiciones implementadas el 15 de octubre de 1754, en lo general, sirvieron para confirmar las mercedes de tierras y los títulos revisados ya a partir de 1692. Siglos después, estas revisiones de tierras ayudarían a los hacendados a defender legalmente sus enormes extensiones territoriales ante los sucesivos gobiernos de México. ${ }^{12}$ Es en el siglo XVII cuando las haciendas de la alcaldía mayor de Poncitlán (cuya sede luego pasó a La Barca) alcanzaron su máxima extensión. En contraparte, como ya se dijo, en estas décadas la población indígena alcanzó su nivel más bajo.

Sin embargo, a diferencia del centro de México, donde para fines del siglo XVI los pueblos se habían visto cercados por las haciendas, comolo han señalado algunos autores, (Semo, 1981: 81), para el caso de la alcaldía mayor de Poncitlán y La Barca, no se produjeron choques entre los intereses de haciendas, ranchos y los pueblos indios por la defensa de sus fundos legales y tierras comunales durante los siglos XVI y XVII. Concatenados los elementos aquí esbozados, lo que se sostiene en este trabajo es que la ausencia de conflictos de tierras durante ese lapso entre las congregaciones indígenas y el resto de actores, tiene que ver fundamentalmente con dos grandes condicionantes: a nivel endógeno; al contar con poca población indígena en su interior, los pueblos pudieron sortear sus necesidades de subsistencia con la tierra disponible, e incluso usarla para renta o dejarla eriaza, como lo demuestran múltiples casos. En segundo lugar, durante el siglo XVII existía aún tierra baldía disponible de ser desmontada y colonizada. Las haciendas aledañas y las llamadas estancias y ranchos de pequeños propietarios mestizos y criollos dedicados principalmente a la ganadería, tuvieron todavía tierras disponibles para expandirse sin chocar aún con las propiedades indígenas. Las mismas actividades de índole extensiva en estas unidades de producción nos señalan que, en general, la tierra no tenía un alto valor en el mercado. Esta situación se trastocó en el siglo XVIII, cuando, si bien los habitantes de los pueblos indios aumentaron, la población no indígena aumentó aún más. En términos de Lockhart (1997), un potencial explicativo de la conflictividad de la época apunta hacia una cambiante proporción entre los indios y el resto de población.

\section{La carencia de la tierra durante el siglo XVIII}

Los siglos XVI y XVII podemos caracterizarlos en lo económico como un parteaguas en la acumulación originaria del capital. Es durante este periodo cuando paulatinamente el imperio español entra en declive. Con la llegada de la dinastía Borbón al poder, se buscó hacer más eficiente la administración y la economía coloniales en beneficio de la metrópoli. Al mismo tiempo, se trató de reducir la corrupción y se acotaron los alcances de 
las autoridades provinciales. En ámbitos más sublimes, las reformas borbónicas del siglo XVIII propiciaron una creciente secularización de la sociedad en las premisas y normas de su conducta colectiva (Connaughton, 1992). A nivel parroquial, al debilitar las corporaciones a favor de un estatus de ciudadano único, se minaron también los supuestos fundamentales bajo los cuales se habían regido tradicionalmente las repúblicas indígenas y se privilegió al individualismo como paradigma de progreso. El siglo XVIII se caracterizó también por un crecimiento poblacional notable; dicho aumento demográfico, por sí mismo, impactó sobre la tenencia de la tierra (Florescano, 1986: 131). John Coatsworth ha señalado que, el crecimiento de la población en la América española durante el siglo XVIII, acrecentó la presión sobre la tierra y engrosó las filas de los forasteros y trabajadores migratorios rebeldes (2010: 49). Para el caso del partido de La Barca, con base en datos de Antonio Gutiérrez de Ulloa, podemos ver que para 1795 se habían logrado alcanzar los 36,200 habitantes (1983: 185); es decir, una cantidad tal vez superior a los nativos encontrados por los españoles en la época de la Conquista. Como consecuencia de ello, las actividades agrícolas se intensificaron y poco a poco la agricultura fue desplazando a la cría de ovejas en los valles. A pesar de que para esta época era difícil encontrar en el área un pueblo con la totalidad de su fundo legal, un aspecto adicional que agravó el problema de tierras fue simplemente una mayor competencia interna por las mismas en virtud del aumento de la población indígena.

Analizando al azar el caso de ocho de los veintitrés pueblos que a fines del periodo colonial estaban comprendidos dentro de la jurisdicción de La Barca, podemos observar que, sumadas en conjunto, las tierras de estos pueblos en 1695 comprendían un total aproximado de 15,980 hectáreas; un siglo después, en 1795, poseían solamente 11,458 hectáreas, es decir, en cien años habían perdido cerca del treinta por ciento de sus territorios. Es relevante, sin embargo, que no fueron los latifundios los antagonistas principales, sino rancheros o haciendas pequeñas los artífices de las disputas contra las congregaciones indígenas. Pequeños asentamientos familiares ubicados a orillas de los pueblos, poco a poco fueron creciendo y demandando espacios a costa de las tierras comunales. Su actitud litigante y dinámica nos habla de que, al menos en lo económico, para el siglo XVIII los habitantes de estas rancherías eran lo suficientemente prósperos como para solventar largos y tortuosos pleitos en aras de hacerse de más tierra, o que, simplemente, se veían obligados a actuar de este modo para poder sobrevivir (ver tabla 1).

Durante el siglo XVIII vemos también una mayor complejidad en la tenencia de la tierra. Por otro lado, si bien las crisis de alimentos por alteraciones naturales fueron recurrentes durante todo el Virreinato, a medida que creció la población debieron ser más desastrosos sus efectos. En los años de 1720-21, 1741-42, 1749-50, 1770-71 y 1785-86, las cosechas fueron malas, hubo escasez general de granos y un aumento de los precios. Enrique Florescano ha demostrado que, durante las crisis más severas, como la de 1785-86, los precios del trigo y el maíz aumentaron hasta un trescientos por ciento (Florescano y Rojas, 1996: 15). A fines de 1785, por ejemplo, el alcalde mayor de La Barca, solicitó la exención del pago de tributos para los pueblos de Poncitlán, San Juan Tecomatlán, Santiago, Santa María, Santa Cruz, San Pedro, Mezcala, San Sebastián, San Miguel y Atotonilco el Alto. Y es que, según su informe, sólo se habían cosechado 1,256 fanegas de maíz, cuando la población aproximada que alimentar era de 2,402 habitantes. Es decir, si aceptamos una equivalencia de sesenta y cinco kilos por fanega de maíz, tendríamos que hubo alrededor de treinta y cuatro kilos de maíz por habitante para subsistir todo el año, o unos ochenta y cinco gramos de maíz por día para cada habitante, lo que equivaldría a lo sumo a tres tortillas para el sustento diario. ${ }^{13}$ Si bien la crisis agrícola impactó a todas las etnias, los pueblos indios la resintieron mucho más por contar con economías esencialmente de autoconsumo. 
Inspiradas en las reformas borbónicas y buscando prevenir estos recurrentes problemas, en el lapso de 17911799, en la Nueva Galicia se expidieron los reglamentos para regular los bienes de comunidad con el fin de que cada pueblo contara con bienes para hacer frente a contingencias como la de 1785-1786 (Tanck, 2010: 18-27). Esta normatividad afectó también la autonomía de los pueblos, en razón de que a partir de entonces se tuvo que pedir permiso a las autoridades de Guadalajara para hacer uso de sus propios recursos.

A fines del siglo XVIII, la situación de los pueblos indígenas de la citada alcaldía era tensa, debido sobre todo a un crecimiento demográfico general y a su cercanía entre sí. En 1796, los indios del pueblo de Cuitzeo litigaban contra rancheros del puesto de Suchitlán por límites..$^{14}$ En 1800, los pueblos de Santa Cruz y Santa María mantenían un pleito contra una ranchería porque al parecer los indígenas buscaban abarcar más tierra de la que les correspondía, ${ }^{15}$ en ese mismo año, el pueblo de Cuitzeo había entrado en un nuevo conflicto, ahora contra un ganadero llamado Joaquín Flores, por el sitio del Potrero, ubicado entre tres pueblos indios inmediatos. ${ }^{16}$

En 1803, Ocotlán tenía invadido parte de su fundo legal por el dueño de la hacienda de Los Gachos. Los pueblos de San Miguel, Santiago y San Pedro Izcán, reclamaban que se les restituyeran sus tierras invadidas en parte por Nicolás Pérez de Vargas, dueño de la hacienda de San Pedro Mártir y otros propietarios españoles. ${ }^{17}$ En ese mismo año, los indígenas de San Miguel y Santiago mantenían otro conflicto contra parcioneros de un rancho llamado San José de Ornelas por la invasión de algunas caballerías de tierra. Los habitantes de San José alegaban estar en posesión de esos predios desde hacía más de dos siglos de antigüedad, lo cual trataron de demostrar - aunque sin documentos-, además de bloquear el acceso del ganado de los indios de San Miguel a los abrevaderos del Río Grande..$^{18}$ Para darnos una idea de la situación, hay que considerar que San José de Ornelas estaba habitado por unas ciento treinta personas, agrupadas en treinta familias fuertemente emparentadas, elemento que sin duda garantizaba una buena organización en los conflictos contra congregaciones indígenas vecinas. ${ }^{19}$

En 1805, los indígenas de La Barca estaban en litigio contra las haciendas de Salame y San José; meses antes del Grito de Dolores, los indígenas de Santa María se quejaban de que sus iguales de Poncitlán les habían invadido su fundo legal. Los testigos en este pleito señalaban, por el contrario, que el pueblo de Santa María había sido fundado sobre las tierras de Poncitlán. De hecho, los indígenas de Poncitlán tenían considerado a Santa María como barrio. ${ }^{20}$ El considerar "barrio" a un pueblo antiguo por su pequeña población era un artilugio frecuente, sobre todo en la segunda mitad del siglo XVIII para descalificar cualquier solicitud de tierras de dichas congregaciones. ${ }^{21}$

Otro aspecto que tendía a volver más complicados los litigios por tierras era necesariamente la pobreza de los núcleos indígenas. Algunas congregaciones eran fuertes y contaban con recursos suficientes para hacer frente a estas contingencias, pero, en general, pocos pueblos indios del occidente de México estaban en esa condición a fines del periodo colonial.

En la segunda mitad del siglo XVIII, comienzan a ser frecuentes los conflictos por límites de tierras entre pueblos. En 1796 el pueblo de La Barca tuvo un conflicto con otros dueños cercanos, los cuales habían invadido tierras de la comunidad, situación que afrontaron con recursos comunes. Sin embargo, el problema se complicó más, dado que indígenas de una congregación de nombre San Pedro Nuevo - ubicado dentro del fundo legal de La Barca- se autoproclamaron pueblo independiente. Los indígenas de La Barca, por su parte, consideraban a San Pedro como barrio y pedían la sujeción formal a su cabecera. Siete años después, en 1803, el conflicto seguía sin resolverse, pero para entonces los de La Barca llevaban gastados 1,800 pesos en jueces, comisionados, agrimensor, gastos de escribano, fiscalía, etcétera; ante ello, solicitaron permiso a la 
Contaduría Real de Guadalajara para utilizar 300 pesos de las arcas de su comunidad para continuar el litigio aunque reconocían que la solución no estaba cerca. El 13 de julio de 1803, por ejemplo, su alcalde se quejaba de que “...es tan remota nuestra esperanza que la vemos como a los principios y seguramente por lo poderoso de nuestros contrarios es poco fondo el de la Arca de la Comunidad pa` contestarles, pues nosotros no tenemos otra cosa de qué valernos....;22 y es que, en 1797 habían solicitado 300 pesos para cubrir los gastos de este pleito; luego, en 1801, habían utilizado otros 600 pesos de su caja de comunidad, a más de otros 346 pesos que habían obtenido del arrendamiento de un predio llamado Potrero Grande. Lo paradójico del caso es que el producto de la renta del Potrero Grande, se dividía entre San Pedro y La Barca por un acuerdo al que habían llegado, y ese dinero, a su vez, les servía a ambos pueblos para seguir litigando entre sí. ${ }^{23}$ Sobra decir que, al igual que en otros casos de la época, al parecer no hubo solución a este asunto.

Hay que tomar en cuenta también que para el caso específico de la Nueva Galicia, la relativa autonomía gozada por las congregaciones que hasta entonces se habían considerado formalmente como indígenas, se vio afectada en todos los órdenes por el crecimiento del resto de etnias en su interior. No hay datos que nos ayuden a vislumbrar el impacto que ello debió tener, por ejemplo, en torno a la desigualdad económica y social al interior de los pueblos; sin embargo, en el siglo XVIII la mayoría de los habitantes considerados como indígenas habían cambiado el náhuatl y otras lenguas por el idioma castellano. Hay datos tangenciales que nos llevan a imaginar al menos dos sectores de población dentro de una misma localidad, es decir, indios y castas, lo cual debió generar conflictos por los recursos y el poder. Como ya se dijo, con el advenimiento de la dinastía Borbón, pero sobre todo a partir de las reformas implementadas durante el reinado de Carlos III (1759-1788), las corporaciones indígenas vieron amenazados con más intensidad sus territorios, sus bienes, sus cajas comunales, sus derechos e identidad. Vemos entonces una época de rápidos cambios sociales, acompañada de privaciones y trastornos que empeoraron la vida de los más pobres (Tutino, 1990: 29).

En síntesis, a diferencia de otras jurisdicciones de la antigua Nueva Galicia, en el caso de los pueblos indios de la alcaldía mayor de Poncitlán y La Barca, los conflictos tienden a ser más complejos a medida que se acerca la Guerra de Independencia. Mientras que los pueblos indios del norte de La Barca, como Atotonilco el Alto, Tototlán o Zapotlán del Rey se enfrentaban con los dueños y administradores de los grandes latifundios locales, con los cuales era difícil litigar por el poder que dichos personajes acumulaban, ${ }^{24}$ hacia las orillas del Río Grande o Santiago los pleitos apuntan en direcciones múltiples, dado que la densidad de asentamientos no permitió en muchos casos la entrega completa de los fundos legales respectivos y, para fines del siglo XVIII, vivían suplicando que se les reintegrara la totalidad de sus tierras.

\section{Reflexiones finales}

En el siglo XVIII las relaciones entre los diversos actores tienden a tensarse por la propiedad de la tierra. Aunado a ello, la tradicional solidaridad organizativa de las comunidades se vio mermada con políticas específicas que buscaron el acotamiento de sus privilegios y el reparto de tierras de modo individual. El siglo XVIII representa también el fin de un largo proceso de repartos de espacios realengos o baldíos iniciado desde la llegada de los primeros conquistadores españoles al occidente de México; las tierras realengas se agotaron. Las últimas demandas de composiciones son por áreas marginales, es decir, cumbres de cerros y barrancas intransitables que difícilmente podían servir para fines productivos. Esta situación se dio a la par de un creciente burocratismo e incapacidad de las estructuras gubernamentales para hacer frente y resolver el 
problema de la tenencia de la tierra. En efecto, sobre todo a partir de la segunda mitad del siglo XVIII, los litigios entre pueblos y rancheros, o entre éstos y las haciendas, se extienden por décadas sin solución. Para esta época, en los expedientes de tierras y aguas del Archivo de Instrumentos Públicos del Estado de Jalisco, abundan los casos en que el promotor de la demanda fallece sin lograr que se emita un dictamen definitivo y el litigio es continuado por sus herederos.

Una hipótesis que haría falta sustentar con más trabajo de archivo es que, a diferencia de otras etapas del Virreinato, los habitantes de las comunidades aquí reseñadas hayan concebido un Estado cada vez más débil y burocrático, cristalizado en el fracaso de las autoridades de la Real Audiencia de Guadalajara para solucionar los problemas por conflictos entre agentes particulares y pueblos, lo cual propició otros atropellos. En otros términos, y coincidiendo con autores como Van Young, es posible que la magnitud de la violencia que se comenzó a percibir a partir de 1810, haya tenido como telón de fondo la idea fundamental de que algo iba mal en el mundo y de que las realidades externas ya no se conformaban al orden moral de la gente del campo (2010: 167-170). Pudo ser precisamente esta especie de exacerbamiento de los indígenas ante la pérdida de sus tierras y de su relativa autonomía, la que propició que comunidades aledañas al Lago de Chapala se hayan levantado en armas casi en bloque meses después de la derrota de Hidalgo en Puente de Calderón y hayan logrado sostener desde 1812 hasta 1816 la resistencia armada sin ser vencidos en la isla de Mezcala (Pérez Verdía, 1989: 110-136), insurrección con claros tintes locales, aunque inserta en la coyuntura del conflicto que le daría la Independencia a México.

\section{Notas}

${ }^{1}$ Véase también: Archivo General de la Nación (en lo sucesivo AGN), Indios, 30, exp. 21.
2 Archivo de Instrumentos Públicos de Jalisco (en lo sucesivo AIPJ), Tierras y aguas, $2^{\underline{a}}$ colección, vol. 25-2, exp. 2l, también Borah (1994: 175-176).

3 AIPJ, Tierras y aguas, 2a colección, vol. 58, exp. 12 y Archivo General de Indias (en lo sucesivo AGI), México, 25, No 48.

${ }^{4}$ AIPJ, Tierras y Aguas, $1^{\underline{a}}$ colección, libro 25-2, exp. 48.

${ }^{5}$ AIPJ, Tierras y aguas, $2^{\underline{a}}$ colección, vol. 187, exp. 13.

${ }^{6}$ Chevalier hace también mención de estas y otras concesiones aledañas al mismo conquistador, destacando que en sus haciendas, Juan de Villaseñor organizaba fiestas tan opulentas que entre los españoles de la época se dio a Huango el sobrenombre de "la corte chica". (1976: 156-157).

${ }^{7}$ AGN, Indiferente colonial, caja 5780, exp. 101.

${ }^{8}$ AIPJ, Tierras y aguas, $2^{\mathfrak{a}}$ colección, vol. 3, exp. 24. ${ }^{9}$ Idem.

${ }^{10}$ AIPJ, Tierras y aguas, $2^{\underline{a}}$ colección, vol. 3, exp. 25.

${ }^{11}$ AIPJ, Tierras y aguas, $1^{\underline{a}}$ colección, libro 25-2, exp. 27; Tierras y aguas, $2^{\underline{a}}$ colección, vol. 246, exp. 8 y vol. 193, exp. 25.

${ }^{12}$ El Archivo Histórico Agrario de Jalisco (en lo sucesivo AHAJ), que posee los expedientes de restitución de tierras a los pueblos y la creación de nuevos ejidos del estado a partir de la Ley Agraria promulgada el 6 de enero de 1915, es prolífico en torno a la revisión de títulos de las grandes haciendas y sus antecedentes de conformación, los cuales casi siempre apelaron a mercedes de tierras concedidas desde fines del siglo XVI y revisadas en los decretos de composiciones del siglo XVII que aquí se señalan. Al igual que las haciendas, a partir de 1915 también los pueblos apelaron a los títulos de sus antiguas tierras, compuestos sobre todo a partir de 1692, siendo casi siempre don Francisco Feijoo (o feixoo) Centellas, oidor y juez supernumerario de ventas y composiciones de tierras de la Nueva Galicia quien les amparó en sus posesiones.

${ }^{13}$ AGN, Tributos, vol. 14, exp. 30.

${ }^{14}$ AIPJ, Tierras y aguas, 2 $2^{\underline{a}}$ colección, vol. 284, exp. 1.

${ }^{15}$ AIPJ, Tierras y aguas, $2^{a}$ colección, vol. 107, exp. 23.

${ }^{16}$ AIPJ, Tierras y aguas, $2^{2}$ colección, vol. 284, exp. 3. 
${ }^{17}$ AIPJ, Tierras y aguas, $2^{2}$ colección, vol. 65, exp. 1.

${ }^{18}$ AIPJ, Tierras y aguas, 2ª colección, vol. 14, exp. 14 y 16.

${ }^{19}$ AIPJ, Tierras y aguas, $2^{\underline{a}}$ colección, vol. 65, exp. 3 .

${ }^{20}$ AIPJ, Tierras y aguas, 2a colección, vol. 107, exp. 22. Véase también AIPJ, Tierras y aguas, $2^{\underline{a}}$ colección, vol. 284, exp. 2. Los testigos a favor de Poncitlán mentían o erraban al referirse a Santa María como barrio fundado en tierras de Poncitlán, ya que, desde mediados del siglo XVII al menos, Santa María estaba considerado un pueblo aparte (Tello, 1945: 116).

${ }^{21}$ Archivo de la Real Audiencia de Guadalajara (en lo sucesivo ARAG), civil, caja 223, exp. 14. Para la Nueva Galicia se pueden mencionar multitud de casos que se encontraban en esta situación. Por ejemplo, a Santiaguito para revocarle una solicitud de tierras en 1803 se le acusó de ser barrio de Poncitlán (cfr. AIPJ, Tierras y aguas, vol. 65, exp. 1.) Al pueblo de Santa Cruz de la Soledad en un litigo contra la hacienda de La Labor, que duró casi todo el siglo XVIII, sus contrarios lo calificaban de ser barrio de Chapala, aunque los indios de Santa Cruz no se reconocían por tales (AIPJ, Tierras y aguas, 2ª colección, vol. 9, exp. 9); en 1808, Santa María Tequepexpan al pedir que se les reintegrara su legua cuadrada de fundo legal, se argumentó no ser procedente su solicitud en razón de ser barrio del pueblo de San Sebastianito (AIPJ, Tierras y aguas, $2^{a}$ colección, vol. 9, exp. 1); en un conflicto entre pueblos, los indígenas de San Gaspar y los de Tonalá acusaron a los indios de Zalatitán de ser "arrimados" al pueblo de Tonalá, de donde luego se autonombraron "barrio", y, por tanto — según el argumento de los de Tonalá y San Gaspar-, los indígenas de Zalatitán no tenían derecho a solicitar tierras. Hay constancia sin embargo, que desde fines del siglo XVI casi todas estas pequeñas congregaciones ya existían y se les daba el carácter de pueblos. Como estos, se podrían seguir señalando más ejemplos.

22 Testimonio de Juan José Benito de Luna, alcalde indígena de La Barca, AIPJ, Tierras y aguas, $2^{2}$ colección, vol. 58 , exp. 10.
${ }^{23}$ AIPJ, Tierras y aguas, 2aㅡ colección, vol. 58, exp. 10.

${ }^{24}$ En una disputa de 1743, entre los indígenas del pueblo de Tototlán y la hacienda de Ciénega perteneciente a Manuel Silvestre Pérez del Camino, las autoridades del pueblo declararon que, a pesar de las vejaciones de que eran objeto, no querían tener problemas con hombres ricos y poderosos como lo era el dueño de la Casa de la Moneda de la Ciudad de México. AIPJ, Tierras y Aguas, 2ª Colección, Vol. 3, exp. 21.

\section{Bibliografía}

Borah, Woldrow (1994), Tenencia de preciosy bienes de tributo real en la Nueva Galicia, 1557-1598, México: El Colegio de Jalisco-El colegio de Michoacán.

Brading, David A. (1993), Mineros y comerciantes en el México borbónico, (1763-1810), México: FCE.

Brading, David, (1988), Haciendas y ranchos del Bajío, México: Grijalbo.

Carbó, Margarita (1996), Evolución histórica de la propiedad comunal, marcojurídico, México: Universidad Autónoma Chapingo.

Chevalier, Francois (1976), La formación de los latifundios en México, México: FCE.

Connaughton, Brian (1992), Ideología y sociedad en Guadalajara (1788-1853), México: UNAM-CNCA.

Coatsworth, John H. (2010), "Patrones de rebelión rural en América Latina: México en una perspectiva comparativa", en Friedrich Katz, (compilador), Revuelta, rebelión y revolución, la lucha rural en México del siglo XVI al siglo XX, México: ERA.

De Arregui, Domingo Lázaro (1980), Descripción de la Nueva Galicia, Gobierno del Estado de Jalisco, Secretaría General, UNED.

De la Mota, Padilla, Matías (1856), Historia de la conquista de la provincia de la Nueva Galicia, Guadalajara, México, Tip. del gobierno a cargo de J. Santos Orosco [documento en electrónico].

Florescano, Enrique y Rafael Rojas (1996), El ocaso de la Nueva España, México: Clío. 
Florescano, Enrique (1986), Los problemas agrarios de México, 1500-1821, México: SEP-ERA.

Frejes, Francisco (1878), Historia breve de los estados independientes del Imperio Mexicano, México: Tip. de S. Banda [documento en electrónico].

Frejes, Francisco (1833), Memoria histórica de los sucesos más notables de la conquista particular de Jalisco por los españoles, Guadalajara, México: Imprenta del supremo gobierno [documento en electrónico].

Gerhard, Peter (1996), La frontera norte de la Nueva España, México: UNAM.

Gupta, Akhil and James Ferguson, (1997), "Beyond Culture: Space, Identity and the Politics of Difference", en Culture, Power, Place. Explorations in Critical Anthropology, Duke University Press, Durham and London.

Gutiérrez de Ulloa, Antonio (1983), Libro de la razón general de la hacienda nacional, de la provincia de Guadalajara, hoy estado libre de Jalisco, México: Gobierno de Jalisco, UNED.

Gutiérrez Santos, Daniel (1955), Historia militar de México, vol. 1, México: Ateneo.

Katz, Friedrich, (2010), "Las rebeliones rurales en el México precortesiano y colonial", en Friedrich Katz (compilador), Revuelta, rebelión y revolución, la lucha rural en México del siglo XVI al siglo XX, México: ERA.

Lameiras, José (1993), "El ritmo de la historia y la región", en Secuencia, revista de historia y ciencias sociales, Nueva Época, núm. 25, Enero-Abril, México: Instituto José María Luis Mora.

Lefebvre, Henri (1991), "La producción del espacio", [documento en electrónico].

Lockart, James (1997), "Provincias del México temprano; variaciones en la evolución regional de Hispanoamérica", en Historias, núm. 38.

Mendieta y Núñez, Lucio (1937), El problema agrario en México, México: Ediciones Porrúa.

Murià José María (1988), Breve historia de Jalisco, Guadalajara: Universidad de Guadalajara.

Pérez Verdía, Luis (1989), Historia particular del estado de
Jalisco, Tomo II, México: Universidad de Guadalajara. Powell, Philip W (1977), La guerra chichimeca, (1550-1600), México: FCE-SEP.

Semo, Enrique (1981), Historia del capitalismo en México, los orígenes, 1521 / 1763, México.

Tanck de Estrada, Dorothy (2005), Atlas ilustrado de los pueblos de indios, México: El Colegio de México, Fomento Cultural Banamex.

Tanck de Estrada, Dorothy (2010), Pueblos indios yeducación en el México colonial, 1750-7821, México: El Colegio de México.

Tello, Antonio (1945), Crónica miscelánea de la sanctaprovincia de Jalisco, Libro IV, Guadalajara: Editorial Font.

Tello, Antonio, (1973), Crónica Miscelánea de la sancta provincia de Jalisco, Libro II, volumen II, Guadalajara: Gobierno del Estado de Jalisco, UdG-INAH.

Tutino, John (1990), De la insurrección a la revolución en México, México: Ediciones ERA.

Van Young, Eric (2010), “Hacia la insurrección: Orígenes agrarios de la rebelión de Hidalgo en la región de Guadalajara", en Friedrich Katz, (compilador), Revuelta, rebelión y revolución, la lucha rural en México del siglo XVI al siglo XX, México: ERA.

Viqueira, Juan Pedro, (1992), "Historia regional: retos y posibilidades", (Conferencia, 9 de diciembre) San Cristóbal de las Casas, Chiapas, México: CIESASSureste-ICHC.

\section{Archivos consultados}

Archivo General de Indias: México, asunto 25, exp. 28.

Archivo General de la Nación: ramo indiferente colonial, caja 5780; ramo de indios, vol. 30; ramo de tributos, vol. 14 .

Archivo de Instrumentos Públicos de Jalisco, ramo de tierras y aguas, $\mathrm{l}^{\mathrm{a}}$ colección, libros: 7 y 25-2; ramo de tierras y aguas, $2^{\mathrm{a}}$ colección, volúmenes: 1, 3, 9, 14, 21, 24, 58, 65, 107, 187, 193, 243, 246, y 284.

Archivo de la Real Audiencia de Guadalajara, ramo civil, caja 223. 
Figura 1. Población indígena estimada en la alcaldía mayor de La Barca (1530-1790).

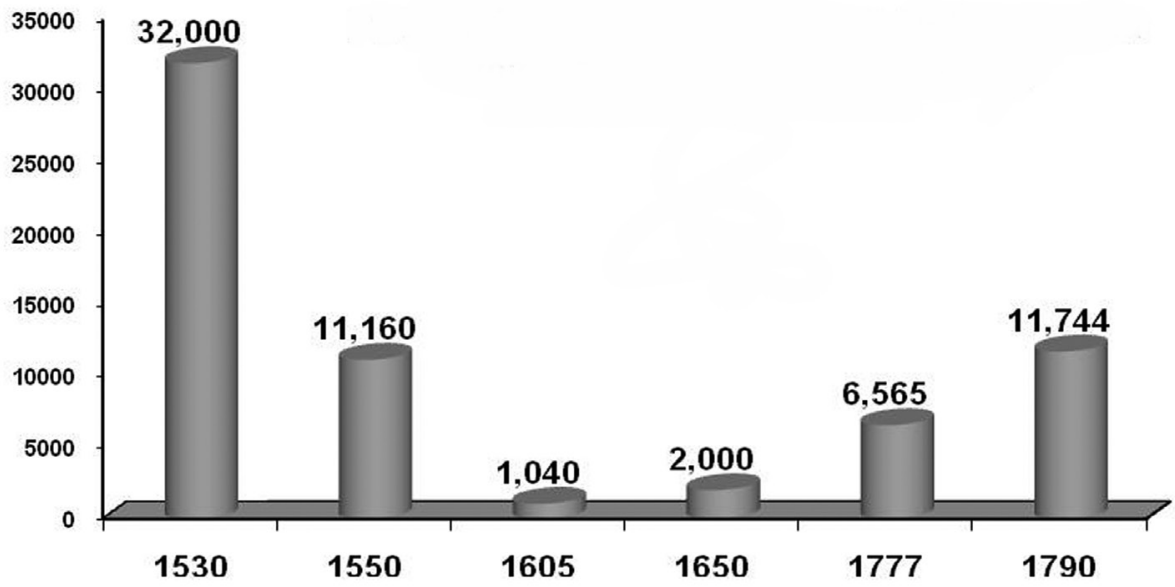

Fuente: Gerhard, 1996: 92-93.

Figura 2. La alcaldía mayor de La Barca a principios del Siglo XVIII.

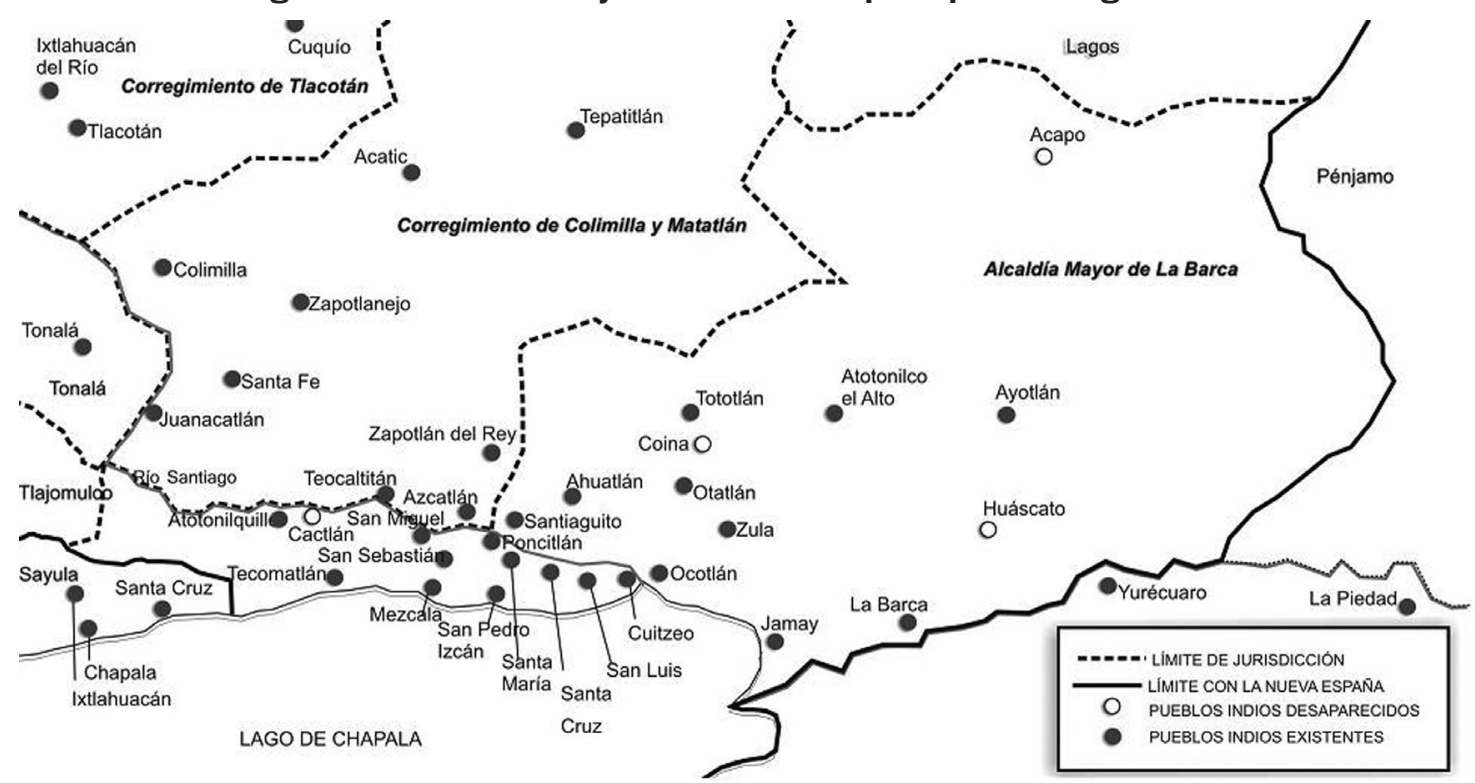

Fuente: Elaboración propia. 
Tabla 1. La alcaldía mayor de La Barca a principios del Siglo XVIII.

\begin{tabular}{|c|c|c|c|}
\hline Población & Tierra detentada en 1695 & Tierra detentada en 1795 & Fuentes de información \\
\hline Atotonilco el Alto & $\begin{array}{l}\text { Su fundo legal, más un } \\
\text { sitio de ganado mayor, es } \\
\text { decir unas 3,510 ha. }\end{array}$ & $\begin{array}{l}\text { Su fundo legal, es decir, } 1,755 \\
\text { ha., el otro sitio lo reclamó una } \\
\text { hacienda llamada Milpillas. }\end{array}$ & $\begin{array}{l}\text { AIPJ, Tierras y aguas, } 2^{\mathrm{a}} \\
\text { colección, vol. } 21 \text {, exp. } 1 \text { y } \\
\text { vol. } 24 \text {, exp. } 3\end{array}$ \\
\hline Cuitzeo & $\begin{array}{l}\text { Su fundo legal }(1,755 \text { ha. } \\
\text { Aproximadamente). }\end{array}$ & $\begin{array}{l}\text { 1,500 ha., en parte de sus tierras } \\
\text { se había fundado una ranchería a } \\
\text { mediados del siglo XVIII. }\end{array}$ & $\begin{array}{l}\text { AIPJ, Tierras y aguas, } 2^{a} \\
\text { colección, vol. } 65 \text {, exp. } 3 .\end{array}$ \\
\hline Otatlán & Su fundo legal. & Su fundo legal. & $\begin{array}{l}\text { AIPJ, Tierras y aguas, } 1^{\text {a }} \\
\text { colección, libro } 7 \text {, exp. } 46 .\end{array}$ \\
\hline San Luis & Su fundo legal. & $\begin{array}{l}\text { 1,000 ha. poco más de medio } \\
\text { sitio de ganado mayor por estar } \\
\text { otros dueños usufructuando parte } \\
\text { de sus tierras }\end{array}$ & $\begin{array}{l}\text { AIPJ, Tierras y aguas, } 2^{a} \\
\text { colección, vol. 3, exp. } 29 .\end{array}$ \\
\hline San Miguel & $\begin{array}{l}\text { Su fundo legal y dos } \\
\text { caballerías, es decir, unas } \\
1,840 \text { ha. }\end{array}$ & $\begin{array}{l}\text { Unas } 1,500 \text { ha. debido a que } \\
\text { para entonces litigaba con } \\
\text { "parcioneros" por el reintegro } \\
\text { completo de su fundo legal. }\end{array}$ & $\begin{array}{l}\text { AIPJ, Tierras y aguas, } 2^{a} \\
\text { colección, vol. 1, exp. } 14 .\end{array}$ \\
\hline Santa Cruz & Su fundo legal. & $\begin{array}{l}\text { Poseían para entonces solo } 3 / 4 \\
\text { de su fundo legal, es decir, unas } \\
\text { 1,316 ha. por invasión del dueño } \\
\text { de la hacienda de Los Gachos. }\end{array}$ & $\begin{array}{l}\text { AIPJ, Tierras y aguas, } 2^{a} \\
\text { colección, vol. } 243 \text {, exp. } 9 \text { y } \\
\text { vol. } 3 \text {, exp. } 28 .\end{array}$ \\
\hline Santiaguito & Su fundo legal. & $\begin{array}{l}1 / 2 \text { sitio de tierra de su fundo } \\
\text { legal, es decir, unas } 877 \text { ha., ya } \\
\text { que la otra parte de sus tierras la } \\
\text { tenía invadida la hacienda de Los } \\
\text { Gachos. }\end{array}$ & $\begin{array}{l}\text { AIPJ, Tierras y aguas, } 1^{\text {a }} \\
\text { colección, libro 25-2, exp. } \\
\text { 1; AIPJ, Tierras y aguas, } 2^{\text {a }} \\
\text { colección, vol. 1, exp. } 14 \text { y } \\
\text { vol. } 65 \text {, exp. } 1 .\end{array}$ \\
\hline Tototlán & $\begin{array}{l}\text { Su fundo legal y unas } \\
\text { caballerías que realmente } \\
\text { pertenecían a la hacienda } \\
\text { de Ciénega. }\end{array}$ & $\begin{array}{l}\text { No hay datos, al parecer solo su } \\
\text { fundo legal. }\end{array}$ & $\begin{array}{l}\text { AIPJ, Tierras y Aguas, 2a } \\
\text { Colección, Vol. 3, exp. 21, } \\
\text { AIPJ, Tierras y Aguas, } 1^{\text {a }} \\
\text { Colección, Libro 7, exp. 46. }\end{array}$ \\
\hline
\end{tabular}

Fuente: Elaboración propia, con base en diversos expedientes del Archivo de Instrumentos Públicos de Jalisco. 